\title{
Édition indépendante, librairie et grande distribution: un tournant décisif
}

Jérôme Meizoz

\section{(2) OpenEdition \\ 1 Journals}

Édition électronique

URL : http://journals.openedition.org/edl/2467

DOI : $10.4000 /$ edl. 2467

ISSN : 2296-5084

Éditeur

Université de Lausanne

\section{Édition imprimée}

Date de publication : 15 mars 2020

Pagination : $237-240$

ISBN : 978-2-940331-73-4

ISSN : 0014-2026

\section{Référence électronique}

Jérôme Meizoz, «Édition indépendante, librairie et grande distribution: un tournant décisif », Études de lettres [En ligne], 312 | 2020, mis en ligne le 24 mars 2020, consulté le 16 septembre 2020. URL : http:// journals.openedition.org/edl/2467 ; DOI : https://doi.org/10.4000/edl.2467 


\section{ÉDITION INDÉPENDANTE, LIBRAIRIE ET GRANDE DISTRIBUTION : UN TOURNANT DÉCISIF}

Le 23 octobre 1980, la Cour d'appel de Paris confirme définitivement un jugement du Tribunal de commerce selon lequel la brochure de quinze pages signée de Jérôme Lindon (directeur des éditions de Minuit), La FNAC et les livres (1978), vendue en librairie en prix de 2 francs, est "consécutive de concurrence déloyale envers la FNAC et contient des passages constituant un dénigrement de nature à lui porter préjudice» (Le Monde, 24 octobre 1980). Désormais difficile à trouver, cette brochure constitue l'une des curiosités du catalogue de la maison Minuit.

Prestigieux éditeur de Beckett, Simon, Duras et Robbe-Grillet, défenseur de la littérature exigeante comme élément du patrimoine à soustraire aux seuls décrets du marché, Jérôme Lindon a prononcé le 9 novembre 1978 dans la cadre de la rencontre «Perspectives du livre et de la distribution" une intervention vigoureuse contre le modèle de rabais pratiqué par la FNAC, entreprise de grande distribution fondée en 1954 dont la première librairie a ouvert à Montparnasse en 1974. L'enseigne y présente 40 '000 ouvrages sur $900 \mathrm{~m}^{2}$ en libre-service et garantit des rabais de $20 \%$ sur le prix catalogue. Avec dix magasins, FNAC devient dès 1980 la plus grande librairie de France.

Dès février 1974, le cofondateur de l'enseigne s'est adressé au ministre de la Culture, lui expliquant que la diminution du prix du livre aurait un effet direct sur la démocratisation des pratiques de lecture. Il reproche aussi aux éditeurs et libraires de pratiquer entre eux une politique de prix défavorable aux clients. Dès 1979, avec l'arrêté Monory dérégulant le prix du livre, les pouvoirs publics renoncent à tout prix de référence conseillé par l'éditeur, pratique traditionnellement en vigueur dans les 
métiers du livre, et c'est au détaillant de le fixer pour chaque ouvrage. En Suisse romande, dès les années 1960, les supermarchés lancent des discounts sur le livre. Mise sous pression, la Société des libraires et éditeurs romands doit réagir en testant également un prix baissé sur certains ouvrages très demandés, notamment Le Petit Larousse et la série des Astérix. En 1979, avec l'arrêté Monory et le projet d'ouverture d'une FNAC à Genève, ce rapport de force gagne en ampleur.

Deux modèles économiques s'opposent donc frontalement lors du procès qui oppose Jérôme Lindon à cette enseigne: celui d'une grande surface baissant le prix des livres grâce à la vente massive d'un type d'ouvrages adaptés à ce type de distribution et celui de la librairie indépendante qui veut maintenir la création exigeante dite "à rotation lente" aux ventes faibles mais durables ${ }^{1}$. Autrement dit, encore, le succès viral d'ouvrage très visibles contre une forme moins spectaculaire de bibliodiversité. Jérôme Lindon prétend que la FNAC, par le discount, ne rend pas service à la chaîne du livre, mais contribue au contraire à faire disparaître le secteur éditorial littéraire, ce patrimoine national de longue durée, aux ventes trop faibles pour les volumes de la grande distribution.

La logique grossiste de la FNAC, sous les dehors généreux du prix baissé, va causer selon l'éditeur la mort de la librairie indépendante, perdante dans cette course aux prix et aux stocks. Examinant le chiffre d'affaires de sa propre maison, il analyse l'évolution de celui-ci durant les quatre premières années de la FNAC (1974-1978) et en tire un «bilan entièrement négatif ${ }^{2}$ pour un éditeur indépendant. Chiffres à l'appui, Lindon montre deux conséquences déjà perceptibles de la logique du discount: elle "restreint le choix des livres offerts au public" et "entraîne une augmentation de leur prix de vente ${ }^{3}$. Et il termine par une déclaration inquiète:

Est-il encore temps d'enrayer l'épidémie qui, après les libraires, tuera les éditeurs indépendants et réduira les créateurs au silence ou à la soumission? Sans doute. Mais le voulons-nous vraiment? Je ne sais: non seulement les civilisations sont mortelles, mais il leur arrive parfois de se suicider ${ }^{4}$.

\footnotetext{
I. J. Lindon, La FNAC et les livres, p. 3.

2. Ibid., p. 12.

3. Ibid., p. 3.

4. Ibid., p. 12.
} 
Avec quelques autres éditeurs indépendants, Jérôme Lindon s'engage en tant que président de l'Association pour le prix unique du livre. La démarche est finalement couronnée de succès et le procès perdu en octobre 1980 n'est qu'une étape de cette longue controverse qui aboutit le 10 août 1981 à la loi Lang sur le prix unique du livre, fruit du jeune gouvernement socialiste. Refusant de considérer les livres comme des produits parmi d'autres, l'État français décide de réguler les tarifs afin de garantir l'égalité du citoyen devant les prix, de maintenir un réseau de distribution diversifié et de soutenir la création d'ouvrages dits «difficiles».

En 2009, un rapport d'Hervé Gaymard tire un bilan positif de cette loi toujours en vigueur aujourd'hui. La FNAC, de son côté, est parvenue à imposer le modèle de la grande surface culturelle et a constamment diversifié ses produits. La librairie Payot, en Suisse romande, a peu ou prou emboîté le pas à ce modèle, en élargissant son offre depuis 2008 avec l'enseigne française Nature \& Découvertes, dont les produits ne relèvent pas de la librairie. Depuis sont apparus d'autres groupes internationaux misant désormais sur la vente en ligne, qui constitue une forme inédite de concurrence pour les librairies physiques et indépendantes.

Jérôme Meizoz

Section de français et Formation Doctorale interdisciplinaire, Faculté des lettres, Université de Lausanne 


\section{BIBLIOGRAPHIE}

Chabault, Vincent, La FNAC, entre commerce et culture. Parcours d'entreprise, parcours d'employés, Paris, PUF, 2010.

Collectif, Le prix du livre, 1981-2006: la loi Lang, Saint-Germain-laBlanche-Herbe, IMEC, 2006.

Corajoud, Carine, La librairie, un commerce pas comme les autres? Histoire de la librairie Payot (1877-1986), thèse de doctorat, Université de Lausanne, 2016, p. 334-341.

Gaymard, Hervé, Pour le livre. Rapport sur l'économie du livre et son avenir, Paris, Gallimard/La Documentation française, 2009.

Gerlach, Markus, Protéger le livre. Enjeux culturels, économiques et politiques du prix fixe, Paris, Alliance des éditeurs indépendants, 2003.

Lindon, Jérôme, La FNAC et les livres. Intervention dans le cadre de la rencontre "Perspectives du livre et de la distribution", le 9 novembre 1978, Paris, Minuit, 1978.

Mollier, Jean-Yves, Édition, presse et pouvoir au XXe siècle, Paris, Fayard, 2008.

PARINET, Élizabeth, Une histoire de l'édition à l'époque contemporaine. $X I X^{e}-X X^{e}$ siècle, Paris, Seuil, 2004.

Vallotton, François, Les batailles du livre. L'édition romande de son âge d'or à l'ère numérique, Lausanne, Presses polytechniques et universitaires romandes, 2014. 